\title{
Effects of agricultural techniques on the quantitative and qualitative characteristics of stevia rebaudiana bertoni, under mediterranean conditions (Karditsa, Thessaly, Greece)
}

\begin{abstract}
Worldwide, Stevia cultivation is increasing steadily, with thousands of hectares being exploited with this natural sweetener plant. The present study represents the first largescale field experiment of the performance of Stevia rebaudiana1 (Bertoni) in Greece, allowing the documentation of a wealth of information regarding the response of this species in a Mediterranean environment. Our experiments were conducted during 2008-2009, in a slightly alkaline soil of 7,6 pH, using a basic 3-3-6 fertilization (N-P-K). We used the Criolla variety and the plants were transplanted at the end of May. We focused particularly on the effect of different planting distances on: the maximum height of plant, the green stem weight, the green leaf weight, the green root weight, the dry stem weight and dry leaf weight. We used six different spacing systems $(60 \times 20,60 \times 40,75 \times 20,75 \times 40,90 \times 40,90 \times 20 \mathrm{~cm})$, for comparison.

Our preliminary results indicate a better plant performance in the $75 \times 40 \mathrm{~cm}$ spacing system. In the spacing system of $60 \times 20 \mathrm{~cm}$, the largest stack of plants compared to the remaining spacing systems, resulted in the greatest amount of harvested material, measured in $\mathrm{kg}$ of dry leaves weight per hectare. The qualitative analysis of the concentration of steviol glycosides (stevioside and rebaudioside-A), 2 revealed that the spacing system $75 \times 40$ also provided the largest concentration of glycosides on plant leaves. By contrast, the largest concentration of total glycoside percentage alone was found in the $60 \times 20$ spacing system. The plants after harvesting were dried by an innovative method we inspired, using the tobacco dryers (Virginia, Burley) and the results gave us leaves of great color. Our experiments should provide the basis for further studies in the Southern Balkans, providing the necessary information for afull-scale domestic stevia cultivation, with significant economic, cultural, and social benefits for Greece.
\end{abstract}

Keywords: stevia cultivation, steviol glycosides, planting distance, spacing system, drying methods, field conditions
Volume 3 Issue 4 - 2016

Panagiotis Zachokostas

Department of Agronomist, Greece

Correspondence: Panagiotis Zachokostas, Department of Agronomist, Bizaniou 26, Greece, Tel +306-977-992-854, Email zachos300@yahoo.gr

Received: February 16, 2016 | Published: May 02, 2016
Abbreviations: Svgly(S), steviol glycoside(S); ST, stevioside; Reb A, rebaudioside A; Vir-Bur Dryers, virginia-burley dryers

\section{Introduction}

The first experiments on Stevia rebaudiana (Bertoni), were conducted in the Greek mainland after 2006. The main object was the discovery of the information regarding the response of these species in a Mediterranean country especially in the regions where the main economical interest is the land cultivation. Apart from the experimentations on the distances of planting, we conducted other experiments regarding the weed control, the fertilization control and the evolution of total SVglys during the development stages of stevia. The most recent experimentation was the response of the leaves, when they are getting dried with the innovative method of the tobacco dryers. There are two main types of tobacco dryers: Virginia and Burleys. The dried leaves were analyzed for their percentage in total SVglys and were compared to leaves that were dried using the traditional methods.

\section{Plant material}

The selected seed for that experiment belongs to the Criolla variety. The seedlings were produced with the float system method. The young seedlings remained in the greenhouse for six to eight weeks depending on their development status. After this period, the seedlings had a height of $15-20 \mathrm{~cm}$ and a thickness of $5-10 \mathrm{~mm}$ and they were ready to be transplanted.

\section{Field selection}

The field selected for that experiment is situated at Karditsa, a city in the mainland of Greece where the main agricultural interests are cotton, wheat, corn and tobacco cultivation. The previous products cultivated at the certain field were tobacco, Virginia variety during 2006 and cotton, Christina variety, during 2007 . The soil was slightly alkaline with a $\mathrm{pH}$ of 7,6 and a basic fertilization of 3-3-6 (parts of N-P-K) was applied.

\section{Experimental design}

The randomized block system was followed, with three replications 
and six treatments, one for each different planting distance. In total we used 18 experimental plots. Each experimental plot size was $180 \mathrm{~m}^{2}$. The first and the last row of plants, as well as the first and last plants between the rows, were used for precautionary reasons. We focused particularly on the effect of different planting distances on the: maximum height of plant, green stem weight, green leaf weight, green root weight, dry stem weight and dry leaf weight. Six different spacing systems were used: $(60 \times 20,60 \times 40,75 \times 20,75 \times 40,90 \times 40,90 \times 20 \mathrm{~cm})$ for comparison. The results were taken 60 days after transplanting and 90days after transplanting just in time for harvest.

\section{Harvesting and drying}

The ideal time to harvest the stevia leaves is when the blooming starts, since at that moment we can achieve the highest percentage of total SVglys in the leaves content. The way to harvest is either by machine or by hand. For the experiment the plants were cut $5 \mathrm{~cm}$ over the surface of the ground and immediately were transferred to the tobacco dryers. Half of them were dried in the Vir-Bur dryers and the rest of them with the traditional method. The plants in the Virginia dryers were dried for 3days, and those in the Burley dryers for 9days. The next step was the separation of the dried leaves from the stems which is much easier than the traditional method, where we separate the green leaves from the green stem. ${ }^{3-6}$

Moreover the dried leaves from the tobacco dryers have a great coloring in contrast to the leaves dried with the traditional method that led us to analyze them for their content in total SVglys. The analysis was carried out by the Institute of Technology for Agricultural Products of Athens. The analysis was performed with the HPLC method. The results showed clearly that the total SVglys percentage of the leaves dried in the tobacco dryers was higher than the respective with the traditional way (Table 1) (Table 2).

Table I Percentages of SVglys in leaves dried with the traditional method

\begin{tabular}{llll}
\hline Spacing system & ST content \% & Reb A content \% & Total \% \\
\hline $60 \times 20$ & 8.4 & 3.9 & 12.3 \\
$60 \times 40$ & 8.7 & 4.1 & 12.8 \\
$75 \times 20$ & 8.6 & 4 & 12.6 \\
$75 \times 40$ & 9.1 & 4.2 & 13.3 \\
$90 \times 20$ & 7.5 & 5.2 & 12.7 \\
$90 \times 40$ & 9 & 4.1 & 13.1 \\
\hline
\end{tabular}

Table 2 Percentages of SVglys in leaves dried with Vir-Bur dryers method

$\begin{array}{llll}\text { Spacing system } & \text { ST content \% } & \text { Reb A content \% } & \text { Total \% } \\ 60 \times 20 & 8.7 & 4.1 & 12.8 \\ 60 \times 40 & 8.9 & 4.2 & 13.1 \\ 75 \times 20 & 8.9 & 4 & 12.9 \\ 75 \times 40 & 9.2 & 4.4 & 13.6 \\ 90 \times 20 & 7.8 & 5.2 & 13 \\ 90 \times 40 & 9.1 & 4.2 & 13.3\end{array}$

\section{Results and discussion}

Quantitative characteristics 60days after transplanting

From the variance analysis concerning the data for the maximum height of plant, the green root weight, the green stem weight and the green leaf weight, no significant differences were observed between the selected spacing systems (Figures 1-4).

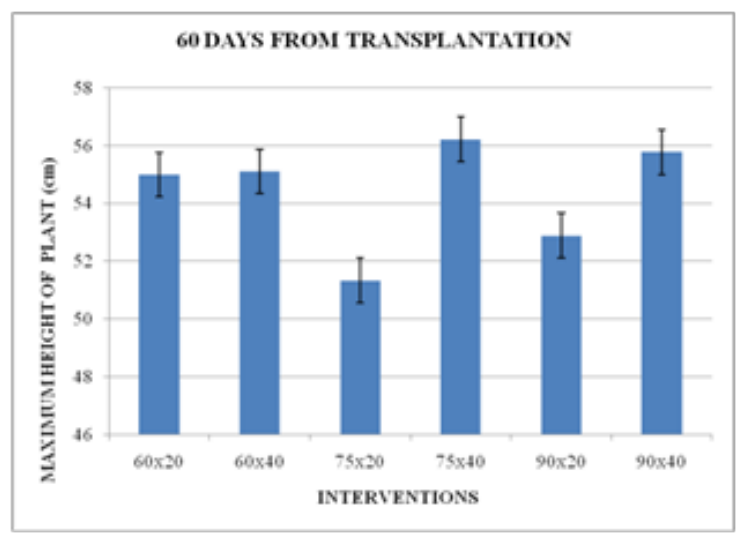

Figure I Maximum height of plant 60 days after transplanting.

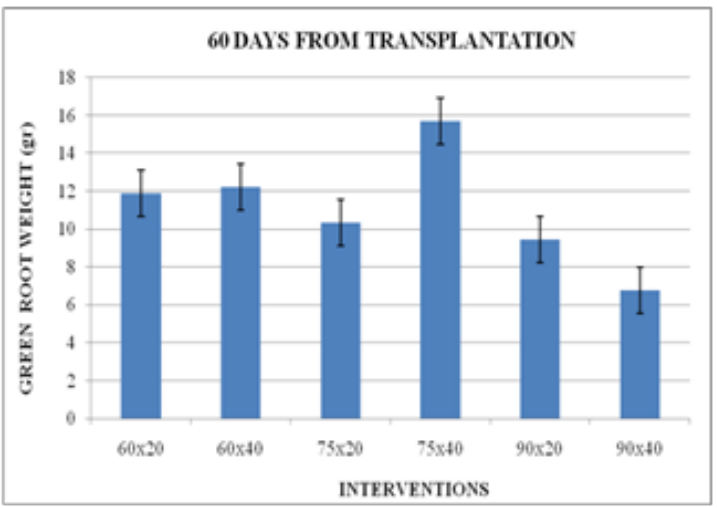

Figure 2 Green root weight of plant 60 days after transplanting.

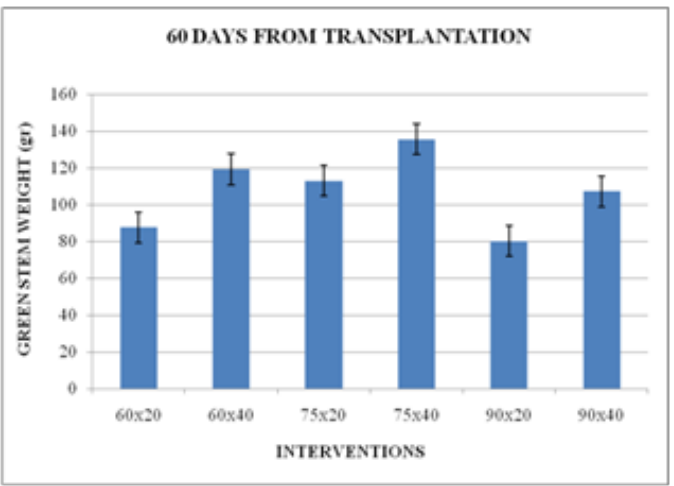

Figure 3 Green stem weight of plant 60 days after transplanting.

\section{Quantitative characteristics 90days after transplanting}

From the variance analysis concerning the data for the maximum height of plant, the green root weight, the green stem weight and the green leaf weight, dry stem weight and dry leaf weight we discovered significant differences between the different spacing systems. There is a significant superiority of the planting distance $75 \times 40$ in contrast to other spacing systems (Figures 5-10). 


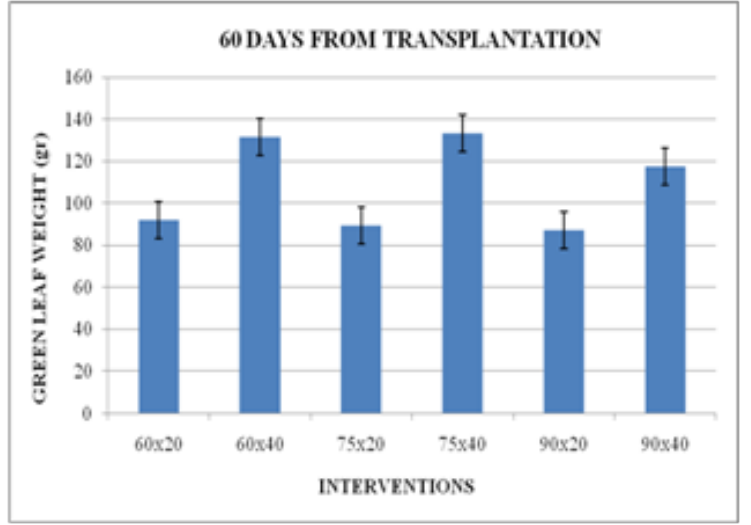

Figure 4 Green leaf weight 60 days after transplanting.

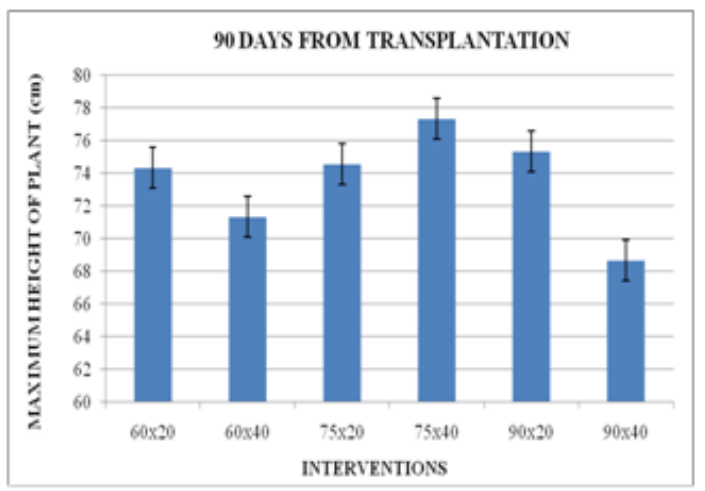

Figure 5 Maximum height of plant 90 days after transplanting.

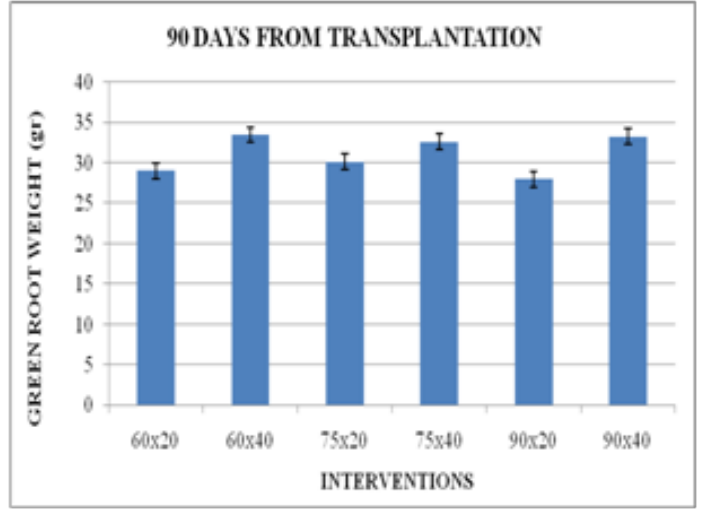

Figure 6 Green root weight of plant 90 days after transplanting.

\section{Qualitative analysis}

After the drying process, the leaves were analyzed for their percentage in total SVglys. The analysis was carried out by the Institute of Technology for Agricultural products and performed with the HPLC method.

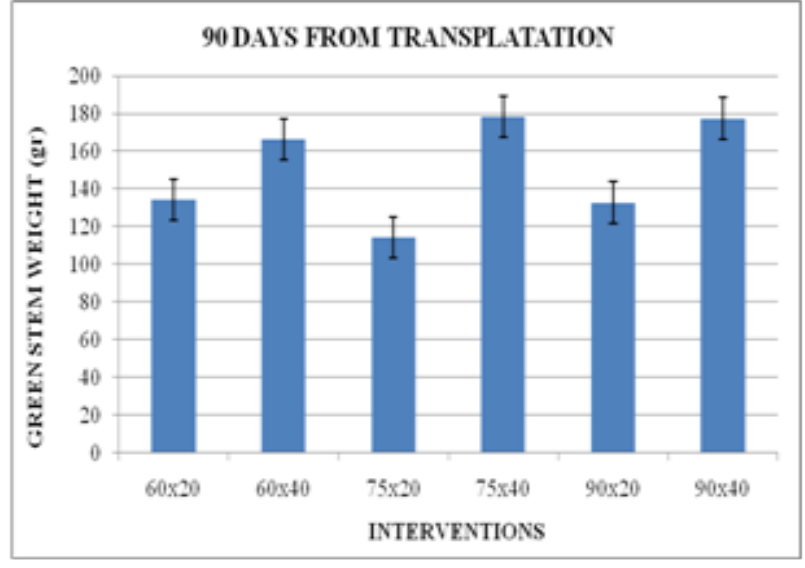

Figure 7 Green stem weight of plant 90 days after transplanting.

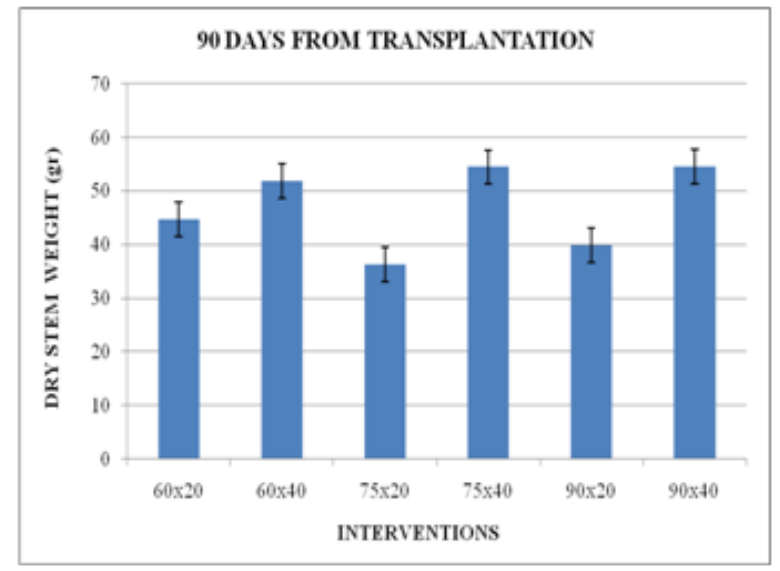

Figure 8 Dry stem weight 90 days after transplanting.

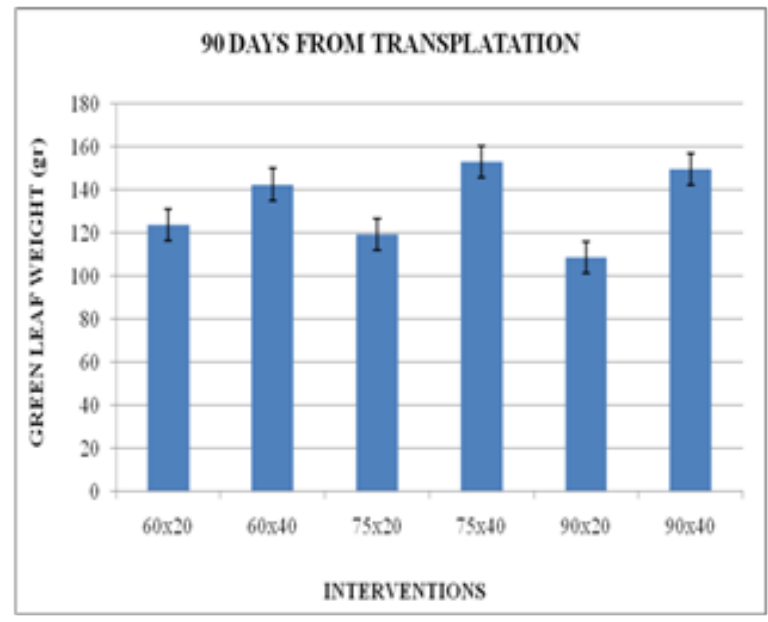

Figure 9 Green leaf weight of plant 90 days after transplanting. 


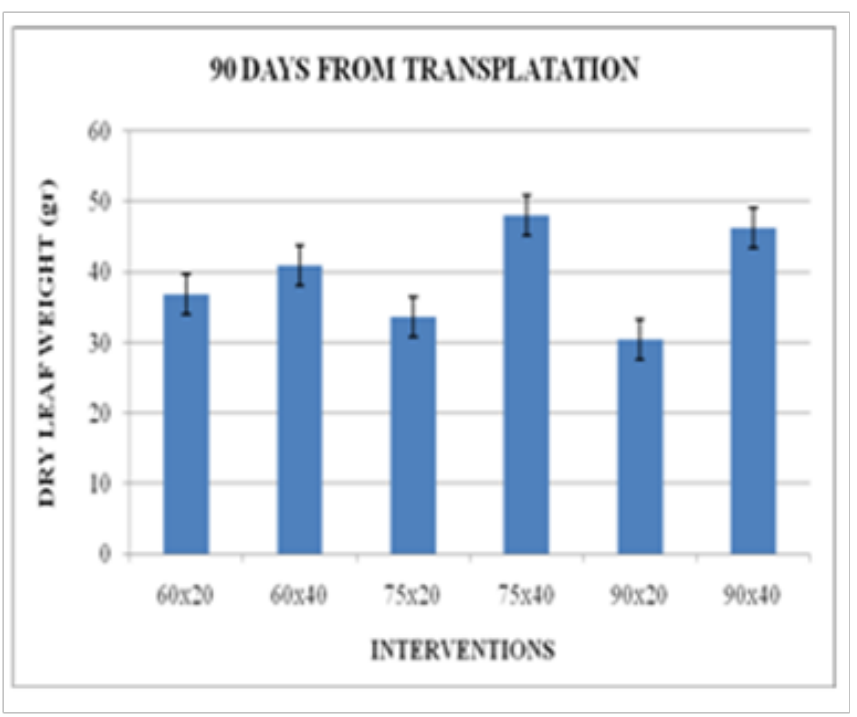

Figure 10 Dry leaf weight 90 days after transplanting.

\section{Conclusion}

From the qualitative and quantitative analysis, we conclude that the $75 \mathrm{x} 40 \mathrm{~cm}$ spacing system gives us the largest concentration of SVglys and the largest amount of harvested material at the individual plant level. However, the spacing system $60 \times 20 \mathrm{~cm}$ seems to be the most appropriate for farming practice, thanks to the largest stack of plants per hectare compared to the spacing system of $75 \times 40 \mathrm{~cm}$ (50,000 plants per hectare less). Hence, harvested material and the concentrated total glycoside will be higher at the per area level for the $60 \times 20 \mathrm{~cm}$ system. Concerning the drying method, that of the tobacco drier was found slightly more productive in glycoside than the traditional method. Therefore, ex-tobbaco farmers could take advantage and reduce the total cost of the stevia cultivation by exploiting the existed infrastructure.

\section{Acknowledgements}

None.

\section{Conflict of interest}

The author declares no conflict of interest.

\section{References}

1. Angkapradipta $\mathrm{P}$, Warsito $\mathrm{T}$, Faturachim D. The N,P,K fertilizer requirements of Stevia Rebaudiana. Menara Perkebunan. Indonesia; 1986.

2. Carneiro JWP, Muniz AS. Greenhouse bedding plant production of Stevia rebaudiana (Bert) Bertoni. Canadian Journal of Plant Science. 1997;77(3):473-474.

3. Chalapathi MV, Shivaraj B. Nutrient uptake and yield of Stevia (Stevia rebaudiana Bertoni) as influenced by methods of planting and fertilizer levels. Crop Research Hisar. Department of Agronomy, Bangalore, India: University of Agricultural Sciences; 1997.

4. Geuns JMC. Proceedings of the 3rd Stevia symposium. Stevia in Europe, Euprint editions, Belgium; 2009.

5. Kinghorn AD. Stevia: the genus Stevia. New York, USA: Taylor \& Franchis; 2002.

6. Zachokostas K, Zachokostas P. Stevia Farming Guide: Nursery. Crops, Drying. Karditsa, Greece; 2012. 